\title{
К ПРОБЛЕМЕ ТОКОВ ЧЕРЕЗ ЗУБЦЫ КОРОТКОЗАМКНУТОГО РОТОРА АСИНХРОННОЙ МАШИНЫ
}

\section{Р. ПАРТС}

Примерно двадщать лет тому назад в электротехнической литературе [1] обсуждался вопрос об изолировании стержней беличьей клетки для того, чтобы уменьшить добавочные потери, которые возникают вследствие протекания тока через зубцы при неизолированной клетке. В статье В. Шуйского $\left[{ }^{2}\right]$ приводится интересный факт о том, как один из первоначальных противников изолирования стержней В. Росмайер высказался все же затем за изолирование.

В настояшее время короткозамкнутые асинхронные машины с алюминиевыми беличьими клетками выпускаются в количестве нескольких миллионов штук в год. Поэтому уменьшение добавочных потерь, составляющих в некоторых случаях 0,5 и более процентов от подведенной к двигателю мощности, представляет практический ннтерес.

Экспериментальная проверка добавочных потерь из-за токов через зубцы весьма затруднительна, особенно при изготовлении беличьей клетки заливкой алюминия пол давленнем. Если беличья клетка отлита, то уже нет возможности для ее изо̃лировәния, или наоборот, если беличья клетка изолирована, то нет возможности для создания путем удаления изоляции любым способом именно того контакта между стержнем и зубцом, который возникает при непосредственной заливке неизолированных стержней.

Проще можно подойти к этой проблеме, рассуждая следующим образом. Поперечные точки через зубцы ухудшают коэффициент полезного действня асинхронной машнны из-за добавочных потерь. Если пойти по пути явного уменьшения зубцового сопротнвления, то эти токи должны возрасти и ухудшение характеристики асинхронной машины должно стать более замет-

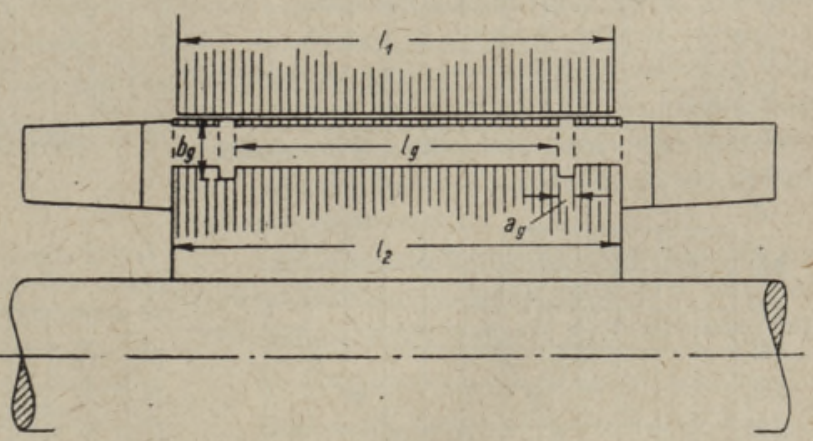

Рис. 1. ной.

С этой целью были изготовлены два пакета из вырубок ротора типа АОТ 52-6 из одной и той же электротехнической листовой стали марки $Э$ 12, из-под одного ін того-же штампа и т. д. Только у части листов второго пакета обрезались зубщы для образования двух дополнительных короткозамыкающих колец (рис. $1, l_{g}=108,5$ м.м, $l_{2}=145$ м.м, $\left.b_{g} \times a_{g}=13,5 \times 4 s t s\right)$.

Рабочие характеристики (рис. $2 a, 6, в, z)$ асннхронной машины с двойными короткозамыкающими кольцами и асинхронной машины. в нормальном исполненин практически совпали. Это дает основанне предполагать, что добавочные потери из-за токов через зубцы короткозамкнутого ротора весьма малы при скольжении $s \leqslant 0,05$. Зато при коротком замыкании произведенное нами изменение конструкции ротора уже сказывается. Әто видно из табл, 1. 
Таблища 1

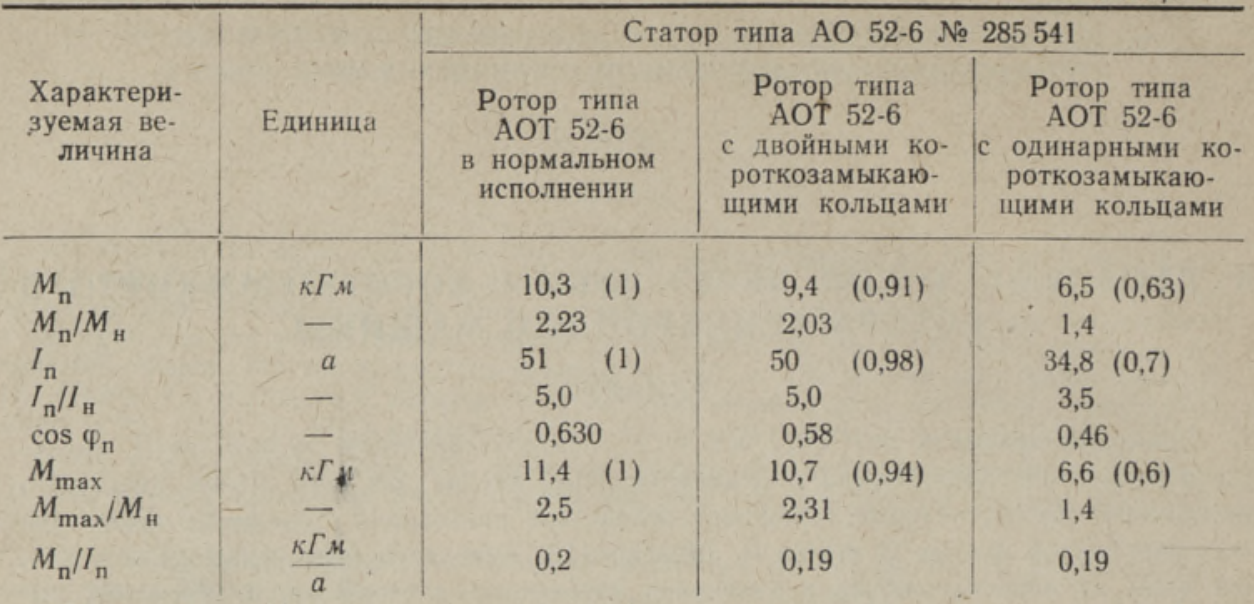

Обозначения: $M_{\mathrm{n}}$ - момент пусковой, $I_{\mathrm{n}}-$ ток пусковой, $\cos \varphi_{\mathrm{n}}-$ пусковой ко-

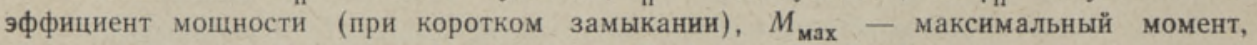
$M_{\text {н }}$ - номннальный момент, $I_{\text {н }}-$ номинальный ток. В табл. 1 , а также в следующей табл. 2, с целью сравнения, для всех двигателей в качестве номинального момента и номинального тока были взяты условно одни и те же номинальные величины асинхрон-
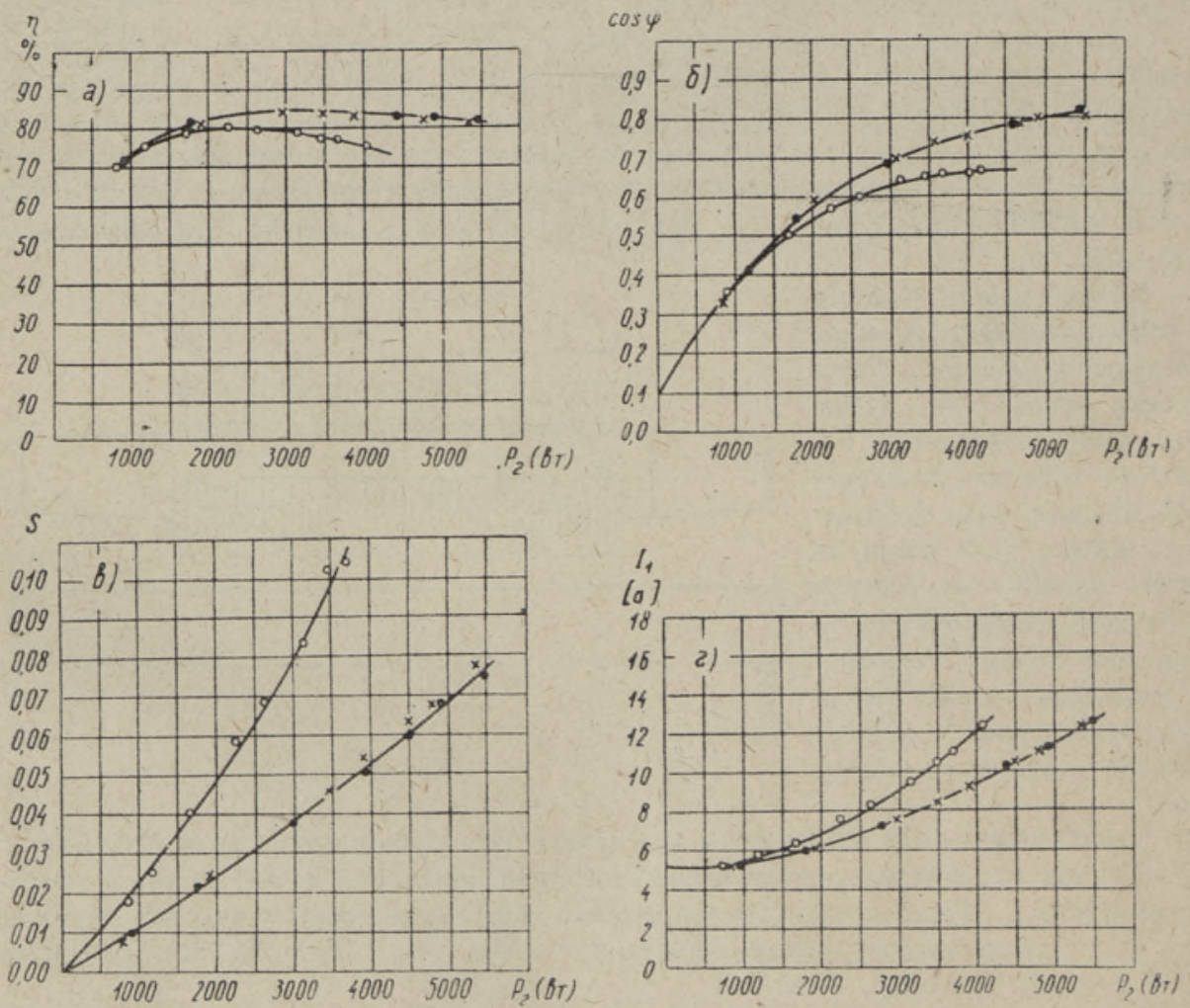

Рис. 2.

$\bullet \bullet$ Статор АO 52-6, ротор АОT 52-6.

$\times \times \times$ Статор АО 52-6, ротор АОТ 52-6 с двойными короткозамыкающими кольцами.

ооо Статор АО 52-6, ротор АОТ 52-6 с одинарными короткозамыкающими кольцами. 
ной машины в нормальном исполнении; в скобках приведены относительные величнны абсолютных значений $M_{\mathrm{n}}, I_{\mathrm{n}}$ и $M_{\text {мax }}$; за базисную единицу прнняты их величины при нормальном исполнении.

Ротор с одинарными короткозамыкаю-

Таблица 2 щими кольцами внутри пакета получен путем сточки торцевых короткозамыкающих колец у ротора с двойными короткозамыкающими кольцами, использованного при указанном в табл. 1 опыте.

В некоторых работах $[3,4]$ рассматриваются токи через зубцы как причина, обуславливающая добавочные потери. Поэтому, по-видимому, полагают, что на схеме замещения ротора параллельно активному сопротивлению короткозамыкающего кольца следует включить активное сопротивление, эквивалентное зубцовому сопротивлению.

Уменьшение коэффициента мощности и пускового тока при коротком замыкании позволяет утверждать, что из-за токов через зубцы изменяется и индуктивное сопротивление ротора. В противном случае невозможно было бы объяснить уменьшение козффициента мощности в случае ротора с одинарными короткозамыкающими кольцами по сравнению с опытом при нормальном исполнении ротора.

$M$

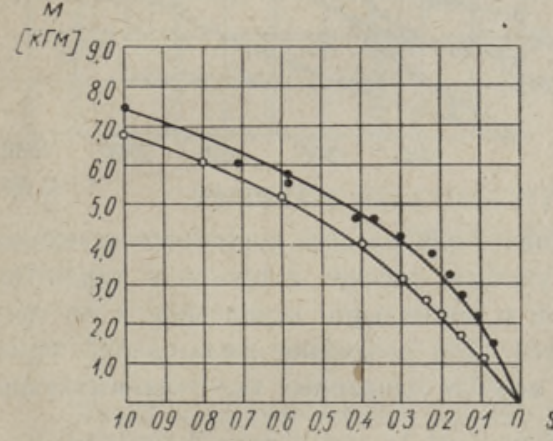

Рис. 3.

○о० АО 52-6, ротор массивный ферромагнитный из стали Ст. 35 .

-• AO 52-6, ротор б́ез короткозамыкающих колец.

Учет добавочных потерь из-за токов через зубцы, как и методы расчета специальных короткозамкнутых асинхронных двигателей с разрезанными короткозамыкающими кольцами [5] могут основываться на надежности контакта между неизолированным стержнем и зубцом. В экспериментальной работе автора [6] подтвердилось наличие надежного контакта между алюминиевыми стержнями, залитыми под давлением, и зубцами пакета ротора, набранного из элекротехнической листовой стали. Это создает предпосылки для создания новых $S$ специальных асинхронных машин, использующих эффект протекания токов через зубцы в той или иной мере.

При испытании асинхронной машины с короткозамкнутым ротором типа АОТ 52-6 после того, когда были сточены короткозамыкающне

кольца (т. е. в случае, когда все токи в стержнях имели единственную возможность замыкаться по зубцам и ярму ротора), механическая характеристика $M=f(s)$ оказалась похожей на часто наблюдаемую механическую характеристику асинхронной машины с массивным ферромагнитным ротором $[7,8]$. При изменении скольжения от единицы до нуля в кривой момента не наблюда. лись провалы (рис. 3).

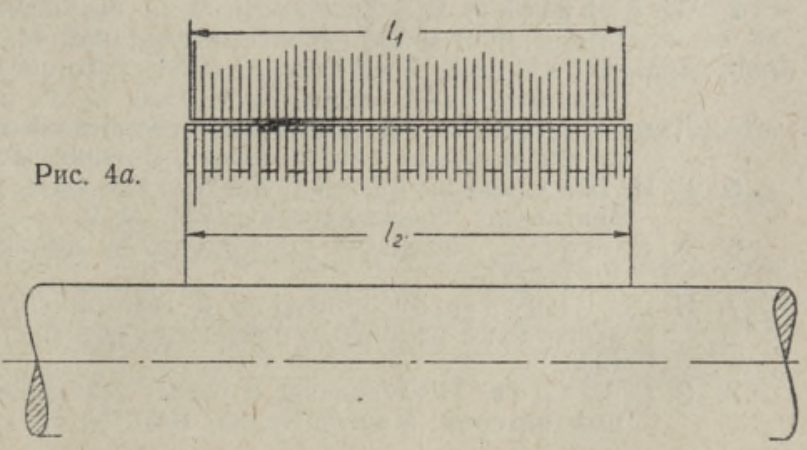




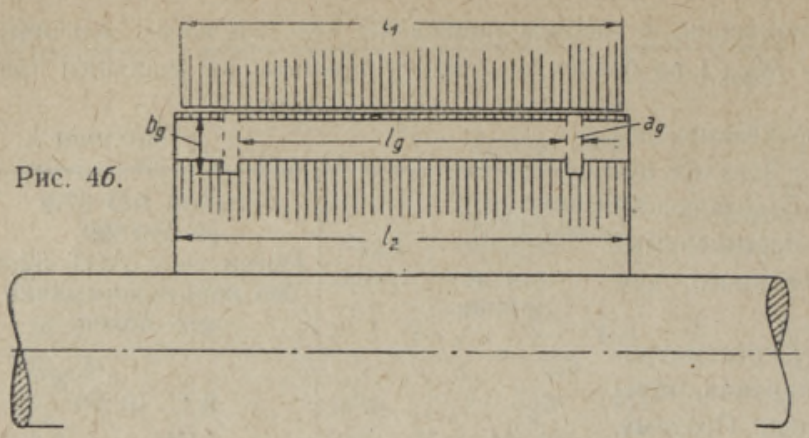

В табл. 2 приведены результаты опыта короткого замыкания асинхронной машнны c ротором без короткозамыкающих колец (рис, 4a), а на рис. 5 ее рабочие характеристики изображены вместе с соответствующими характеристиками асинхронной машины $c$ ротором, имеющим одинарные короткозамыкающие кольща внутри пакета (рис. 46).

Рнс. 5.

оо АО 52-6, ротор с одинарными короткозамыкающими кольщамн (рис. 46).

- АО 52-6, ротор без короткозамыкающих колец (рис. $4 a$ ).

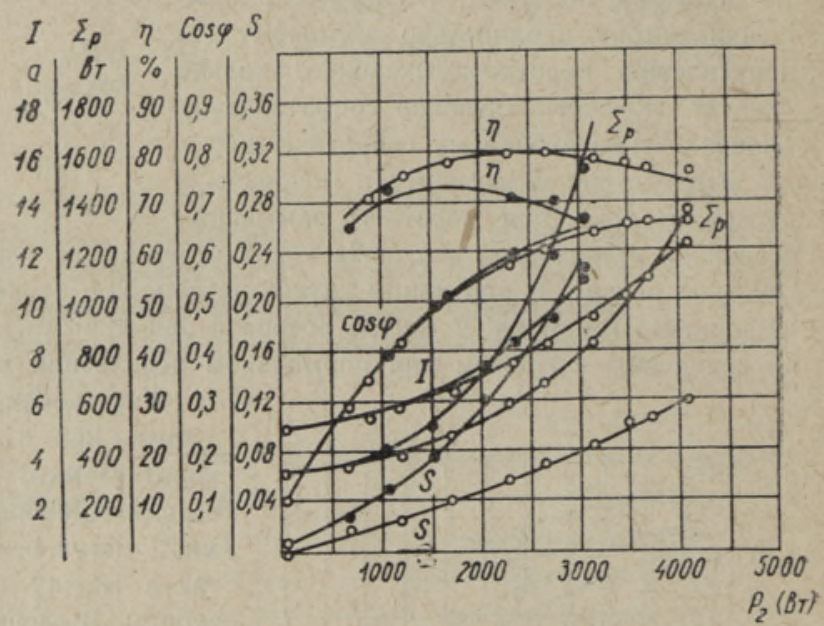

По рнс, 2 и 5 вндно, что асннхронная машина с одинарными короткозамыкающими кольцами дает возможность получать промежуточные рабочие и пусковые характеристики по сравнению с асинхронными машинами в нормальном исполнении и по сравнению с теми-же без короткозамыкающих колец. Для получения желательной характеристики можно варьировать расположение и сечение одинарных короткозамыкаюшнх колец.

По своей механической характеристнке короткозамкнутая асинхронная машина без короткозамыкающих колец может заменить асннхронную машину с ферромагнитным ротором.

\section{Л И Т Е Р Т У Р А}

1. Б. П. Ап а ров, Теоретические основы проектирования асинхронных двигателей. Докторская диссертация, 1937.

2. W. Schuisky, Die Zusatzverluste in der unisolierten Käfigwicklung. Bulletin de l'Association suisse des electriciens, 1953, 44, 7, 330.

3. A. M. O d o k, Stray-Load Losses and Stray Torques in Induction Machines, AIEE, Power Apparatus and Systems, April, 1958, № 35, p. 43.

4. Ладислав Цыганек, Контактное сопротивление между стержнями алюминиевой клетки и сталью пакета ротора. Вестник электропромышленности, 1960, № 6.

5. Г. И. Ш т у р а н. Разомкнутые беличьи клетки в короткозамкнутых асинхронных двигателях. Электричество, 1951, № 9.

6. R. R. P a rts, Lōhestatud lühisrōngastega asünkroonmootorid. Tehnika ia Tootmine, 1959 , nr. 3.

7. Н. В. Синев а, Теоретическое и экспериментальное исследование асинхронного двнгателя с массивным омеденным ротором (кандидатская диссертация), МЭИ. 1956.

8. В. С. Ш а ров, Исследование и расчет асинхронного двигателя с массивным стальным ротором. Электричество, 1959, № 4.

Институт энергетики

Академии наук Эстонской ССР

Поступила в редакцию

25. XI 1961 


\title{
ASUNKROONMOOTORI LUHISMÄHISEGA ROOTORI HAMMASTES TEKKIVATE VOOLUDE PROBLEEM
}

\author{
R. Parts
}

Resümee

Peaaegu kakskümmend aastat tagasi arutati elektrotehnilises kirjanduses lühismähisega rootori varraste isoleerimise küsimust, et vähendada asünkroonmootoris lisakadusid, mis tekivad läbi rootori hammaste kulgevate vooludega.

Autor on antud probleemile püüdnud läheneda teisest seisukohast ja püstitanud küsimuse, kas läbi hammaste kulgevaid voole on võimalik ära kasutada asünkroonmootori koormuskarakteristika ja ka teiste ekspluatatsiooniliste parameetrite muutmiseks. Eksperimentaaltöödeks valmistati samaaegselt kaks rootorit - üks tavaline ja teine topeltlühisrōngastega (joon. 1). Kuigi viimasel lisalühisrōngas vähendab tunduvalt hammaste takistust, ei erinenud nende masinate koormuskarakteristikad praktiliselt sugugi (joon. 2). Nähtavasti on läbi hammaste kulgevate voolude môju antud konstruktsiooniga rootori puhül mootori koormuskarakteristikale tühine, kui rootori libisemine ei ületa 0,1 .

Läbi hammaste kulgevad voolud mōjustavad rohkem mootori käivitusrežiimi iseloomustavaid suurusi (tab. 1).

Asetades lühisrōnga rootori paketi sisse (joon. 46), vōib asünkroonmootori karakteristikaid muuta väga laiades piirides.

Huvitava tulemuse andis ilma lühisrõngasteta rootoriga asünkroonmootori katsetamine (joon. 4a): sellise mootori momendikōver osutus paremaks massiivse ferromagnetilise rootoriga asünkroonmootori omast. See loob eeldused massiivsete ferfomagnetiliste rootorite asendamiseks joonisel 4 kujutatuga neis täiturmootorites, mille pöörlemiskiirus ei ületa piiri, kus rootoris tekivad lubamatud mehhaanilised pinged.

\section{Eesti NSV Teaduste Akadeemia Energeetika Instituut}

Saabus toimetusse

25. XI 1961

\section{PROBLEM OF CURRENTS FORMED IN THE ROTOR TEETH OF AN ASYNCHRONE-MOTOR}

\section{R. Parts}

\section{Summary}

About some two decades ago the problem was presented in electrotechnical literature of isolating the rotor bars of an asynchrone-motor so as to reduce additional losses in the asynchrone-motor, which are formed by currents passing through the rotor teeth.

The author has tried to approach the problem from another side, and namely by discussing whether it is not possible to utilize the currents passing through the rotor teeth so as to change the operation characteristics and other exploitational parameters of the asynchronemotor. For experimental purposes two rotors were constructed - a usual one and another having double end rings (fig. 1). Though the resistance of the rotor teeth of the latter was considerably reduced by additional rings, the operation characteristics of those two motors did not practically differ from one another (fig. 2). Seemingly, in the case of a rotor with the given construction the effect of the currents passing through the roter teeth on the operation characteristics is very inconsiderable if the slipping of the rotor does not exceed 0.1 .

The currents passing through the rotor teeth affect to a greater extent the values characterizing the starting regime of the motor (table 1).

By'placing an end ring into the rotor pack (fig. 4б), the characteristics of an asynchrone-motor may be changed within a very considerable range.

An interesting result was obtained in the experiment with the motor having a rotor without any end rings (fig. $4 a$ ): the moment curve of this motor proved to be better than that of an asynchrone-motor with a massive ferromagnetic rotor. This fact creates prospects for replacing massive ferromagnetic rotors in a servo-motor with those as shown in fig. 4 . whose revolving velocity does not exceed the limits which may cause undesirable mechanical tensions. 